\title{
Erratum to: A High-Voltage High-Frequency Subnanosecond Pulse Generator Based on Gallium Arsenide Drift Step-Recovery Diodes
}

\author{
A. V. Rozhkov ${ }^{a, *}$ \\ ${ }^{a}$ Ioffe Physical Technical Institute, Russian Academy of Sciences, St. Petersburg, 194021 Russia \\ *e-mail:rozh@hv.ioffe.rssi.ru \\ Received November 9, 2021; revised November 9, 2021; accepted November 9, 2021
}

DOI: $10.1134 / \mathrm{S} 0020441221060208$

The article "A High-Voltage High-Frequency Subnanosecond Pulse Generator Based on Gallium Arsenide Drift Step-Recovery Diodes”, written by A. V. Rozhkov, was originally published electronically in SpringerLink on 14 September 2021 without Open Access. After publication in volume 64, issue 5, pages 680-682 the authors decided to make the article an Open Access publication. Therefore, the copyright of the article has been changed to (C) The Author(s) 2021 and the article is forthwith distributed under the terms of a Creative Commons Attribution 4.0 International License (http://creativecommons.org/licenses/by/4.0/, CC BY), which permits use, duplication, adaptation, distribution and reproduction of a work in any medium or format, as long as you cite the original author(s) and publication source, provide a link to the Creative Commons license, and indicate if changes were made.

The original article can be found online at https://doi.org/10.1134/S0020441221040230 